\title{
Brasil: dilemas e desafios da política externa
}

\section{CELSO LAFER}

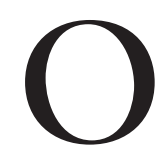

BRASIL TEM uma especificidade que é parte de sua identidade no âmbito mundial. É, pelas suas dimensões, um país continental como a Rússia, a China, a Índia e os EUA. É por esta razão que George F. Kennan, em Around the Cragged Hill, ao pensar sobre o tema das dimensões na experiência política norte-americana, inclui o Brasil junto com estes países na categoria de monster country, considerando, na construção desta qualificação, além dos dados geográficos e demográficos, os dados econômicos e políticos e a magnitude dos problemas e dos desafios (1). É precisamente a magnitude destes problemas e de seus desafios do ângulo de política exterior brasileira o que me proponho a examinar neste texto. Como hoje é muito significativa a diluição entre o interno e o externo, ao discutir estes problemas e desafios, estarei discutindo temas que estão no cerne dos dilemas da agenda nacional.

O Brasil é, evidentemente, muito diferente da China e da Índia, países asiáticos de cultura milenar; da Rússia, situada entre a Ásia e a Europa e de presença relevante desde séculos na cultura e na política européia e internacional e dos EUA - hoje a única superpotência no plano mundial apta a atuar simultaneamente nos campos da paz e da guerra, no econômico e no dos valores. Além desses e de muitos outros aspectos que claramente nos diferenciam dos países continentais acima mencionados, cabe ressaltar que o Brasil, por situar-se na América do Sul não está, e nunca esteve, em sua história, na linha de frente das tensões internacionais prevalecentes no campo estratégico-militar. Por isso, para voltar a Kennan, não é um monster country assustador.

Não é, também, um monster country assustador porque, à luz de sua história e de suas circunstâncias, tem um estilo de comportamento internacional que se configura, como observa Gelson Fonseca Jr., por uma moderação construtiva que se expressa na capacidade "de desdramatizar a agenda de política exterior ou seja de reduzir os conflitos, crises e dificuldades ao leito diplomático" (2). Esta moderação construtiva está permeada por uma leitura grociana da realidade internacional, nela identificando, sem ingenuidades, um ingrediente positivo de sociabilidade que permite lidar com o 
conflito e a cooperação por meio da diplomacia e do direito (3). A continuidade e a persistência no tempo deste tipo de conduta diplomática é um legado da obra do Barão do Rio Branco. Com efeito, Rio Branco solucionou o primeiro problema de toda política externa que é a da delimitação das fronteiras nacionais pois equacionou, com virtú e fortuna, por meio do direito e da diplomacia os limites do país com os seus inúmeros vizinhos. Este fato contrasta, por exemplo, com a situação da Rússia, China e Índia, que até hoje têm problemas de fronteiras e, por conta disso, guerrearam e foram guerreados no correr de sua História e com a situação dos Estados Unidos, que como superpotência tem uma visão planetária de suas fronteiras.

A consolidação pacífica do espaço nacional liberou o país para fazer do desenvolvimento o tema básico da política externa brasileira no correr do século XX. Criou igualmente as condições para que o Brasil estivesse à vontade e em casa com o componente sul-americano de sua identidade internacional, ou seja, como diria Ortega y Gasset, com a sua circunstância. Esta é assim uma força profunda, de natureza positiva, de sua política externa, que no século XX esteve basicamente voltada, no contexto regional, para o entendimento entre os países sul-americanos. Este entendimento buscou transformar fronteiras-separação em fronteiras-cooperação, o que em tempos mais recentes se traduziu em fazer não apenas a melhor política mas a melhor economia de uma geografia como, por exemplo, vêm fazendo os europeus, desde a década de 1950, no seu processo de integração. O paradigma deste processo de transformação do papel das fronteiras na América do Sul é o Mercosul, resultado de uma efetiva reestruturação de natureza estratégica, do relacionamento Brasil-Argentina e grociano "pilotis da organização de toda a América do Sul”, na avaliação do presidente Fernando Henrique Cardoso (4).

Estes dados de inserção geográfica e de experiência histórica do Brasil, que se deram no eixo das relações da relativa igualdade entre os estados, são relevantes na discussão dos atuais dilemas e desafios da política exterior do país. Estes têm como um dos seus componentes fundamentais as transformações ora em curso no plano mundial, e que configuram a maneira pela qual opera o eixo da assimetria ou seja o do nosso relacionamento com estados e sociedades dos quais nos separam, como aponta Rubens Ricupero, "um diferencial apreciável de poderio político e econômico" (5).

Estas transformações são muito significativas e, neste contexto, a queda do muro de Berlim pode ser considerada um evento inaugural. Assinala, em conjunto com o término da União Soviética, como entende Hobsbawm, o fim do curto século XX (6) e, portanto, o começo histórico do novo 
século e o mergulho no novo milênio. A queda do muro sem dúvida representa, nos seus desdobramentos no correr da década de 90, uma mudança do paradigma do funcionamento do sistema internacional, tal como se configurou no pós-Segunda Guerra Mundial. De fato, a vida internacional deixou de ter como elemento estruturador as polaridades definidas das relações Leste/Oeste; Norte/Sul. Passou a caracterizar-se por polaridades indefinidas, sujeitas às forças profundas de duas lógicas que operam numa dialética contraditória e de mútua complementaridade: a lógica da globalização (das finanças, da economia, da informação, dos valores etc.) e a lógica da fragmentação (das identidades, da secessão dos estados, dos fundamentalismos, da exclusão social etc.).

A interação entre uma lógica integradora do espaço mundial e uma dinâmica desintegradora e contestadora desta lógica, tem muito a ver com as assimetrias do processo de globalização. Estas realçam a percepção das descontinuidades no sistema internacional que, de um lado, exprimem um descompasso entre significado e poderio e, de outro, traduzem um inequívoco déficit de governança do espaço do planeta.

Diante destas novas realidades e dos seus problemas, como é que se vem situando o Brasil? Preliminarmente, creio que é importante mencionar que a sociedade brasileira mudou significativamente a partir de 1930, em função de um conjunto de políticas públicas, inclusive a política externa, inspirada, como diria Helio Jaguaribe, por um "nacionalismo de fins", voltado para o desenvolvimento do espaço nacional (7). Em função do projeto do "nacionalismo de fins" voltado para a integração interna do grande espaço nacional, o Brasil urbanizou-se, industrializou-se, democratizou-se, diversificou sua pauta de exportações, ampliou seu acervo de relações diplomáticas. Em síntese, modernizou-se e melhorou seu locus standi internacional sem, no entanto, ter equacionado uma das falhas de sua formação, que o "nacionalismo de fins" também buscava solucionar, que é o persistente problema da exclusão social.

A década de 1980, no plano interno, foi politicamente bem sucedida com a transição do regime militar para a democracia. No campo econômico, o país assistiu, em meio à crise da dívida externa e à inflação, ao esgotamento do dinamismo do modelo de substituição de importações, que foi o lastro do "nacionalismo de fins".

Esse esgotamento se tornou ainda mais inequívoco com as mudanças ocorridas no plano internacional, depois da queda do muro de Berlim. Com efeito, sob o impacto da diminuição dos custos dos transportes e da comunicação e dos avanços em computação, a lógica da globalização permitiu, 
pela inovação tecnológica, diluir o significado financeiro e econômico das fronteiras, esgarçando a diferença entre o interno e o externo. Num mundo de polaridades indefinidas, tal esgarçamento colocou em questão a eficiência e o dinamismo do processo de internalização das cadeias produtivas, mediante uma inserção controlada do país na economia mundial, que era uma idéia-força do "nacionalismo de fins". De fato, a lógica da globalização, além de ter acelerado vertiginosamente os fluxos financeiros, ensejou uma desagregação das cadeias produtivas em escala planetária. Converteu o out sourcing numa prática empresarial rotineira e fez do comércio exterior e da produção de bens e serviços, as duas faces de uma mesma moeda (8). Por esta razão, tornou-se inoperante o desenvolvimento no relativo distanciamento de uma inserção na economia mundial gerido pelo Estado, anteriormente viabilizado pela escala continental do país e operado pela lógica do "nacionalismo de fins". O mundo que o Brasil administrava como uma externalidade, internalizou-se, encerrando assim a eficácia do repertório de soluções construídas a partir do primeiro governo de Getúlio Vargas, que configurou o país no século XX. Daí o reordenamento das agendas interna e externa que caracterizou a vida política e econômica do país na década de 90.

O desafio da nova agenda é o de transformá-la num caminho através do qual, no contexto de uma globalização assimétrica, o país amplie o poder de controle sobre seu destino e, com sensibilidade social-democrática, encaminhe o persistente problema da exclusão social.

O que significa este desafio do ponto de vista da política externa concebida como uma política pública voltada para o tema do desenvolvimento do espaço nacional? Creio, com Gelson Fonseca Jr., que se antes o país construiu, com razoável sucesso, a autonomia possível pelo relativo distanciamento em relação ao mundo, na virada do século esta autonomia possível, necessária para o desenvolvimento, só pode ser construída pela participação ativa na elaboração das normas e pautas de conduta da gestão da ordem mundial (9). Em outras palavras, os interesses específicos do país estão, mais do que nunca, atrelados aos seus interesses gerais na dinâmica do funcionamento da ordem mundial. É por esta razão que a obra aberta da continuidade na mudança, que caracteriza a diplomacia brasileira, requer um aprofundamento nos foros multilaterais da linha da política externa, inaugurada, por Rui Barbosa, em Haia, em 1907. Esta se traduz em obter no eixo assimétrico das relações internacionais do Brasil um papel na elaboração e aplicação das normas e das pautas de conduta que regem os grandes problemas mundiais, que tradicionalmente as grandes potências buscam avocar e, na medida do possível, exercer com exclusividade. 
Esta linha foi uma constante da diplomacia brasileira no correr do século XX. Resultou da capacidade do Brasil de, como potência média de escala continental e de relevância regional, articular consensos entre grandes e pequenos e trabalhar pela possibilidade da harmonia. O locus standi para este aprofundamento tem a sustentá-lo a coerência de uma conduta diplomática de corte grociano e o fato de ser o Brasil um país relevante para a tessitura da ordem mundial e apto para articular consensos porque não é um monster country assustador, como os seus congêneres. Isto é um ativo potencial num sistema internacional permeado por descontinuidades e com um forte déficit de governabilidade. A isto se adicionam os investimentos no soft-power da credibilidade, realizados pelo país no correr da década de 90 , ao tratar de maneira construtiva - pela participação e não pela distância os temas globais que se inseriram, em novos termos, na agenda internacional pós-Guerra Fria. Entre eles destaco meio-ambiente, direitos humanos e nãoproliferação nuclear, ponderando que no plano dos valores este trato construtivo e de articulação de consensos é compatível com o componente Ocidente da nossa identidade internacional, congruente com a visão grociana que permeia a nossa conduta diplomática e viável à luz da nossa inserção no mundo.

Este trato construtivo se deu em foros multilaterais. Estes são para o Brasil, pelo jogo das alianças de geometria variável, possibilitadas por um mundo de polaridades indefinidas, o melhor tabuleiro para gerar poder pela ação conjunta, permitindo ao país exercitar a sua competência na defesa dos interesses nacionais. É neste tipo de tabuleiro que reside o melhor do nosso potencial para atuar na elaboração das normas e pautas de conduta da gestão do espaço da globalização no campo econômico, no qual reside o nosso maior desafio.

Com efeito, do ponto de vista do desenvolvimento do espaço nacional e do tema da pobreza, que é um componente da nossa identidade internacional, como um "outro Ocidente", mais pobre, mais problemático, mas não menos Ocidente, na formulação de José Guilherme Merquior (10), o desafio real que se coloca para o Brasil, no plano mundial, reside nas negociações da agenda financeira e da agenda de comércio exterior. Isto é assim, pois se é verdade que a globalização encurtou os espaços e acelerou o tempo, esta aceleração do tempo afeta o Brasil de maneira não uniforme.

O tempo financeiro é o tempo on line dos fluxos financeiros, que na sua volatilidade vêm produzindo, nos países de mercados emergentes, as sucessivas crises que nos atingiram direta ou indiretamente. Daí a relevância para o Brasil das negociações sobre a nova arquitetura financeira. 
O tempo da midia é também um tempo on line. Provoca, no Brasil e no mundo, a repercussão imediata do peso dos eventos nas percepções coletivas. Esta repercussão fragmenta a agenda da opinião pública, leva ao monitoramento e a reações constantes aos sinais do mercado e da vida política. Conseqüentemente, cria um ambiente de excessiva concentração no momento presente, em detrimento da necessária atenção às suas implicações futuras. $\mathrm{O}$ foco nos eventos e a falta de foco nos processos, provenientes da natureza do tempo da mídia, é um desafio constante para a construção do soft-power da credibilidade internacional do país - um desafio que adquire outra magnitude para o Brasil no sistema internacional pós-Guerra Fria, com a internalização do mundo na realidade brasileira. Daí, por exemplo, a importância da diplomacia presidencial e das reuniões de cúpula, que vêm sendo conduzidas pelo presidente Fernando Henrique Cardoso e que são uma expressão da diplomacia aberta, criando eventos que permitem transmitir e informar a opinião pública - interna e internacional - sobre o significado dos processos em andamento no país (11).

O tempo econômico é o do ciclo da produção e do investimento. É um tempo mais lento que o financeiro e o da mídia e, no caso do Brasil, afetado pelas condições sistêmicas da competitividade. Estas sofrem o peso das ineficiências do assim chamado "custo Brasil", um custo que era suportável quando o mundo era passível de ser administrado como externalidade. Lidar com o "custo Brasil" é uma necessidade proveniente da internalização do mundo. Isto requer reformas como, por exemplo, a tributária e a da previdência social.

Estas reformas transitam pelo tempo politico, que no Brasil e no mundo é um tempo distinto do financeiro, do da mídia e do econômico. É, em princípio, num regime democrático, um tempo mais lento, condicionado pela territorialidade das instituições políticas, pelos ciclos eleitorais, pelos interesses dos partidos e, no caso do Brasil, pelo problema do complexo equilíbrio dos estados da Federação, num país caracterizado pelo pluralismo de sua escala continental. É também, no caso brasileiro, um tempo tradicionalmente voltado para dentro e não para fora, à luz da experiência histórica de um país continental habituado à autonomia pela distância e que, por isso mesmo, ainda não absorveu a internalização do mundo. Daí a razão pela qual a sincronia do tempo político com os tempos financeiro e econômico é um dos grandes desafios na condução das nossas políticas públicas.

Este desafio tem uma dimensão que passa pelo tempo diplomático, que no caso das negociações comerciais multilaterais é um tempo mais lento. É neste tempo, que é por excelência o da OMC, que o Brasil como um 
pequeno global trader precisa ampliar o seu acesso a mercados. Precisa também obter espaço, que se vem reduzindo, para a condução de suas políticas públicas. Com efeito, num país como o nosso, o desenvolvimento não resultará, automaticamente, da combinação virtuosa das políticas fiscal, monetária e cambial, embora nelas encontre as condições macroeconômicas de sua sustentabilidade. Requer um conjunto de políticas públicas que, de maneira congruente e compatível com os grandes equilíbrios macroeconômicos, asseguradores da estabilidade da moeda, reduzam a desigualdade e impulsionem o desenvolvimento do espaço nacional, dando no seu âmbito, aos agentes econômicos, condições de isonomia competitiva, que lhes permita enfrentar o desafio da globalização (12).

Em síntese e para concluir com uma metáfora musical, o desafio da política externa brasileira, no início do século XXI, é o de buscar condições para entoar a melodia da especificidade do país em harmonia com o mundo. Não é um desafio fácil dada a magnitude dos problemas internos do país, as dificuldades de sincronia dos tempos na condução das políticas públicas e a cacofonia generalizada que caracteriza o mundo atual, em função das descontinuidades prevalecentes no funcionamento do sistema internacional. É, no entanto, um desafio para o qual o histórico da política externa brasileira, que é um amálgama das linhas de continuidade com as da inovação, numa obra aberta voltada para construir o futuro, oferece um significativo lastro para a ação bem-sucedida.

Notas

1 George F. Kennan, Around the Cragged Hill: a Personal and Political Philosophy. New York, Norton, 1993, p.143.

2 Gelson Fonseca Jr., A legitimidade e outras questões internacionais: poder e ética entre as nações, São Paulo, Paz e Terra 1998, p. 356.

3 Cf. Martin Wight, International Theory: the Three Traditions. Gabriele Wight \& Brian Porter (eds.). Leicester, Leicester University Press, 1991; Pier Paolo Portinaro, Il realismo politico, Roma-Bari, Laterza, 1999; Hedley Bull, Benedict Kingsbury \& Adam Roberts (eds.), Hugo Grotius and International Relations, Oxford, Clarendon Press, 1992; Celso Lafer, Discurso de posse no cargo de ministro de Relações Exteriores, em 13 de abril de 1992; A inserção internacional do Brasil; A autoridade do Itamaraty, in A inserção internacional do Brasil: a gestão do ministro Celso Lafer no Itamaraty. Brasilia, MRE, 1993, p.31-37; $285-293 ; 375-387$ 
4 O presidente segundo o sociólogo: entrevista de Fernando Henrique Cardoso a Roberto Pompen de Toledo. São Paulo, Cia. das Letras, 1998, p. 127.

5 Rubens Ricupero, A diplomacia do desenvolvimento, in João Hermes Pereira de Araújo, Marcos Azambuja \& Rubens Ricúpero, Três ensaios sobre a diplomacia brasileira. Brasilia, MRE, p.193-194.

6 Eric Hobsbawm, The Age of the Extremes. New York, Pantheon Books, 1994.

7 Hélio Jaguaribe, O nacionalismo na atualidade brasileira. Rio de Janeiro, ISEB, 1958 , p.52.

8 Gilberto Dupas, Economia global e exclusão social. São Paulo, Paz e Terra, 1999.

9 Gelson Fonseca Jr., A legitimidade e outras questões internacionais, cit. p. 363374.

10 José Guilherme Merquior, El otro Occidente, in Felipe Arocena \& Eduardo de León (orgs.) El complejo de Próspero: ensayos sobre cultura, modernidad y modernización en America Latina. Montevideo, Vintén Edit., 1993, p. 109110.

11 Sérgio Danese, Diplomacia presidencial. Rio de Janeiro, Topbooks Edit. 1999.

12 Desenvolvimento, indústria e comércio: debates - estudos - documentos. Relatório de Atividades, 1 de janeiro a 16 de julbo de 1999 do Ministro Celso Lafer no MDIC. São Paulo, FIESP/CIESP, Instituto Roberto Simonsen, 1999.

Celso Lafer é professor da Faculdade de Direito da USP. 